\title{
The Diagnosis of Drug-induced Liver Injury: Current Diagnostic Ability and Future Challenges of the Digestive Disease Week-Japan 2004 Scale 15 Years after Its Proposal
}

\author{
Masaaki Watanabe ${ }^{1}$, Akitaka Shibuya ${ }^{2}$, Hiroaki Yokomori ${ }^{3}$ and Wasaburo Koizumi ${ }^{4}$
}

\begin{abstract}
:
Objective This study examined whether or not the Digestive Disease Week-Japan (DDW-J) 2004 scale proposed over 15 years ago can be applied to current cases of drug-induced liver injury (DILI).

Methods The new patients group included 125 patients from 2012 to 2019 and was divided into 2 subgroups: 96 patients in the new DILI group and 29 patients in the new non-DILI group. Similarly, the old patients group included 105 patients from 1997 to 2002 and was divided into 2 subgroups: 59 patients in the old DILI group and 46 patients in the old non-DILI group. Patients were assessed by the DDW-J 2004 scale; those with a score $\geq 3$ were defined as having DILI.

Results The total score of the new DILI group was significantly lower than that of the old DILI group [6 (1-11) vs. 6 (3-9), $\mathrm{p}=0.004]$. The sensitivity, specificity, positive predictive value, and negative predictive value (NPV) were $94.8 \%, 65.6 \%, 90.1 \%$, and $79.2 \%$, respectively, in the new patients group and $100 \%$, $91.4 \%, 93.7 \%$, and $100 \%$, respectively, in the old patients group. The specificity and NPV of the new patients group were significantly lower than those of the old patients group.

Conclusion The DDW-J 2004 scale maintains a stable diagnostic ability for DILI, regardless of differences in eras and verification methods. However, differential diagnoses can affect the scoring, and new types of DILI, such as immune-related adverse events, must be addressed. Therefore, upgrading the scale should be considered.
\end{abstract}

Key words: adverse effect, diagnosis, Digestive Disease Week-Japan 2004 scale, drug-induced liver injury, Roussel Uclaf Causality Assessment Method

(Intern Med 60: 2557-2568, 2021)

(DOI: 10.2169/internalmedicine.6370-20)

\section{Introduction}

Drug-induced liver injury (DILI) due to prescription medicines, herbal medicines, over-the-counter drugs, health foods, and supplements is a liver disorder that is encountered on a daily basis. Most patients experience a good course due to the early, accurate diagnosis and discontinuation of the causative drug. However, some patients experience serious complications, such as fulminant hepatitis, requirement for liver transplant, and even death.
In Japan, the first diagnostic criteria for DILI were established in $1978(1,2)$. At that time, the principle pathogenic mechanism of DILI was thought to be an allergic reaction of the liver to drugs. Therefore, the criteria included the following immunoallergic features: a suggestive clinical course after drug administration; symptoms related to drug allergy, such as a fever, rash, and pruritus; eosinophilia $\geq 6 \%$ in the peripheral blood; suggestive drug-induced lymphocyte stimulation test (DLST) results; and reappearance of liver injury following re-administration of the causal drug $(1,2)$. However, a national survey of DILI conducted in the latter

\footnotetext{
${ }^{1}$ Department of Gastroenterology, Kitasato University Medical Center, Japan, ${ }^{2}$ Department of Risk Management and Health Care Administration, Kitasato University School of Medicine, Japan, ${ }^{3}$ Department of General Internal Medicine, Kitasato University Medical Center, Japan and ${ }^{4}$ Department of Gastroenterology, Kitasato University School of Medicine, Japan

Received: September 23, 2020; Accepted: January 25, 2021; Advance Publication by J-STAGE: March 15, 2021

Correspondence to Dr. Masaaki Watanabe, masaaki@kitasato-u.ac.jp
} 
half of the 1990s in Japan revealed diversity in the mechanisms, causative drugs, time to the onset of DILI, and course after the onset $(1,3)$. The mechanisms underlying DILI are classified as direct hepatotoxicity and idiosyncratic hepatotoxicity $(4,5)$. In addition, indirect hepatotoxicity related to autoimmune mechanisms has come to be considered an emerging type (4). With this increased understanding of DILI, the previous diagnostic criteria, which were biased toward allergic features, became insufficient for diagnosing current DILI cases in Japan $(1,2)$.

Diagnostic criteria that could be used for any type of DILI were proposed by the International Consensus Meeting (ICM) in 1990 (6) and later revised to the Roussel Uclaf Causality Assessment Method (RUCAM) scale [previously called the Council for International Organizations of Medical Sciences (CIOMS) scale] in 1993 (7). The RUCAM scale is a scoring system that considers the relationship between the drug intake and onset, clinical course after cessation of the drug, risk factors, concomitant use of drugs, differential diagnosis of alternative liver diseases, any previous information regarding the hepatotoxicity of the drug, and response to unintentional reexposure (7).

Beginning in the early 2000s, there was an opportunity in Japan to propose a diagnostic scale based on the RUCAM scale that matches the actual condition of DILI in Japan. At Digestive Disease Week-Japan 2002 (DDW-J 2002) in Yokohama, Japan, which was jointly organized with the 6th General Meeting of the Japan Society of Hepatology (JSH) held in 2002, speakers from six institutions, including the author, presented data from actual DILI cases and designed a new draft of DILI diagnostic criteria (1). After further verification (2) and revision, the DDW-J 2004 scale was proposed with consensus at DDW-J 2004 in Fukuoka, Japan, jointly organized with the 8th General Meeting of the JSH in 2004 (8). The DDW-J 2004 scale was created and validated based on actual DILI cases available at that time. Of particular note, the DDW-J 2004 scale was designed to be easy and convenient for physicians other than hepatologists to use $(8,9)$. Since then, the DDW-J 2004 scale has been frequently cited as a common measure for DILI in Japan in both case reports and clinical research. The English version of the digital object identifier (DOI) is currently available online at doi: $10.1111 / j .1872-034 X .2008 .00400$ (10).

However, a recent prospective study in Japan indicated that the clinical features of and pathogenic mechanism underlying DILI have changed $(11,12)$. In addition, many drugs with novel mechanisms of action were developed after the introduction of the DDW-J 2004 scale. Therefore, the DDW-J 2004 scale requires timely verification in order to support DILI in the current era.

The present study clarified the current clinical circumstances of DILI and evaluated whether or not the DDW-J 2004 scale, which was proposed over 15 years ago, can still be applied to current DILI cases.

\section{Materials and Methods}

Patients were retrospectively aggregated using the medical record management systems of two different hospitals during two different eras. This study includes two patient groups. The "new patients group" consists of individuals who were enrolled between February 2012 and August 2019 at Kitasato University Medical Center (Kitamoto, Saitama, Japan), and the "old patients group" consists of individuals who were enrolled between March 5, 1997, and December 26, 2002 (i.e., before the DDW-J 2004 scale was introduced) at Kitasato University East Hospital (Sagamihara, Kanagawa, Japan).

The new patients group and old patients group were further subclassified as the new DILI group, new non-DILI group, old DILI group, and old non-DILI group, respectively, by three experts according to whether they had DILI or another liver disease based on the definitions described below; H. Yokomori and A. Shibuya were involved in the assignment of patients into the new and old patients group, respectively, and $\mathrm{M}$. Watanabe validated the selection of all patients. DILI was defined as liver injury associated with drug administration. The clinical features, clinical course, and differential diagnosis of other possible causes of liver injury were evaluated comprehensively, with the final diagnosis of the experts defined as the gold standard for DILI. This approach was based on a previous report that demonstrated the superiority of expert opinions in the diagnosis of DILI (13).

Non-DILI was defined as follows: liver disease that differed from DILI, was diagnosed by experts, and occurred in patients with a history of medication use for any symptoms or underlying illness at the time liver injury was first detected. Typical non-DILI included liver diseases listed as a target for differentiation on the DDW-J 2004 scale, namely acute viral hepatitis associated with hepatitis A virus (HAV), hepatitis B virus (HBV), hepatitis C virus (HCV), EpsteinBarr virus (EBV), or cytomegalovirus (CMV); biliary tract disease; alcoholic liver disease (ALD); and shock liver. In addition, the following diseases that were suspected initially or confirmed later by experts were classified as non-DILI: chronic liver diseases, e.g. chronic viral hepatitis associated with $\mathrm{HBV}$ and $\mathrm{HCV}$; autoimmune liver diseases, such as autoimmune hepatitis (AIH) and primary biliary cholangitis (PBC); and metabolic disorders, such as nonalcoholic fatty liver disease (NAFLD).

Using this classification, the new patients group consisted of 96 patients with new DILI and 29 with new non-DILI, while the old patients group included 59 with old DILI and 46 with old non-DILI group (Fig. 1).

For each era, we created $2 \times 2$ contingency tables for DILI or non-DILI as defined by experts and for patients with scores $\geq 3$ (possible or high possibility) or $\leq 2$ (low possibility) as determined by the DDW-J 2004 scale. The sensitivity, specificity, positive predictive value (PPV), and negative pre- 


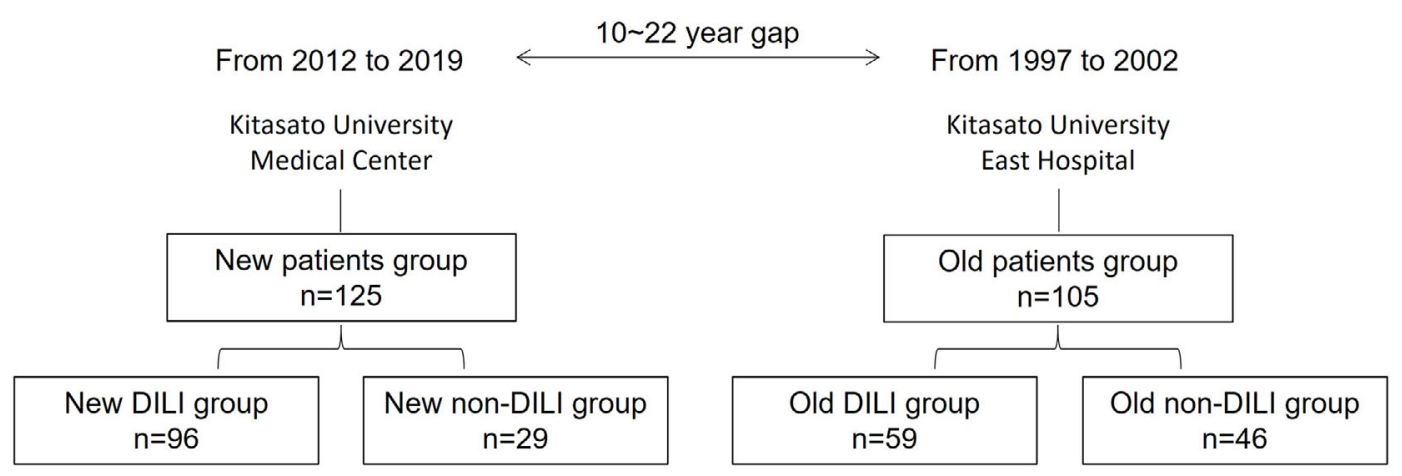

Figure 1. Patients enrolled in this study. There was a 10- to 22-year gap between the 2 patient groups. New patients group: Patients with liver disease since 2012. New DILI group: Patients with drug-induced liver injury (DILI) since 2012. New non-DILI group: Patients who received medication for liver diseases other than DILI since 2012. Old patients group: Patients with liver disease before 2004. Old DILI group: Patients with DILI before 2002. Old non-DILI group: Patients who received medication for liver diseases other than DILI before 2002 .

dictive value (NPV) for the new and old patients groups were calculated.

\section{Data collection and limitations}

This study was a retrospective study. The new and old patients groups were enrolled in two different hospitals. For the new patients group, data were collected from medical records. However, medical records from most of the patients in the old patients group were not generally available. Therefore, their data were acquired from previously published papers and the contents of previous conference presentations $(2,14,15)$. Furthermore, the degree of liver damage in patients in the new patients group varied from mild to severe due to advances in medical record management systems. However, the data for the old patients group were primarily collected from patients who were hospitalized.

\section{Statistical analyses}

Categorical patient background variables and differences in sensitivity, specificity, PPV, and NPV were analyzed by Fisher's exact test or $\chi^{2}$ test. Quantitative patient background variables and scores calculated by the DDW-J 2004 scale were analyzed by the Mann-Whitney U test. All statistical tests were performed with the Ekuseru-Toukei 2015 software program (Social Survey Research Information, Tokyo, Japan).

\section{Statement of ethics}

To obtain patient consent, an opt-out method was adopted prior to inclusion in this study. This study was approved by a suitably constituted Ethics Committee at our facility and conformed to the provisions of the Declaration of Helsinki.

\section{Results}

Table 1 lists current and past DILI and non-DILI conditions as well as patient background characteristics.

The new patients group (including both the DILI and
non-DILI subgroups) was older than the old patients group. Serum levels of alanine aminotransferase (ALT) and total bilirubin were higher in the old DILI group than in the new DILI group. Regarding the DILI type, hepatocellular type was more commonly observed than the cholestatic or mixed type in the new DILI group.

Some differences in items that might influence the DDWJ 2004 scale scoring were observed. With respect to the period from drug exposure to the onset of liver injury, no differences between the new and old DILI groups were observed. In contrast, this period was less relevant to the course of DILI in the new non-DILI group than in the old non-DILI group. Regarding the onset pattern, onset during the administration of the causative drug was more predominant in the new patients group than in the old patients group. Regarding the course after cessation of the drug, the period from drug discontinuation to the improvement of liver injury was shorter in the new DILI group than in the old DILI group. With respect to risk factors, because no pregnant women were enrolled in this study, only a history of alcohol use was subject to review. There was no marked difference in the history of alcohol use between the new and old DILI groups. In contrast, patients in the new non-DILI group were more likely to have a history of alcohol use than those in the old non-DILI group, suggesting that ALD may have been more prevalent in this group than in others. Regarding the search for non-drug causes, the exclusion diagnoses for group I diseases (HAV, HBV, HCV, ALD, gallbladder and biliary tract disease, and shock liver) and group II diseases (EBV and CMV) specified in the DDW-J 2004 scale were compared. Patients in the new DILI group were less completely surveyed for group I and II diseases than those in the old DILI group. Previous information on drug hepatotoxicity was available for $88.7 \%$ of drugs but often unavailable for unidentified agents, such as dietary supplements. The frequency of eosinophilia did not differ markedly between the new and old DILI groups when patients without eosinophil counts were included. A DLST was per- 
Table 1. Patient Backgrounds.

\begin{tabular}{|c|c|c|c|c|c|c|}
\hline & \multicolumn{2}{|c|}{ New patients group } & \multicolumn{2}{|c|}{ Old patients group } & \multicolumn{2}{|c|}{ Differences ( $\mathrm{p}$ value) } \\
\hline & New DILI group & $\begin{array}{l}\text { New non-DILI } \\
\text { group }\end{array}$ & Old DILI group & $\begin{array}{l}\text { Old non-DILI } \\
\text { group }\end{array}$ & $\begin{array}{l}\text { New DILI } \\
\text { group vs. } \\
\text { Old DILI } \\
\text { group }\end{array}$ & $\begin{array}{l}\text { New non-DILI } \\
\text { group vs. Old } \\
\text { non-DILI } \\
\text { group }\end{array}$ \\
\hline Number of patients & 96 & 29 & 59 & 46 & & \\
\hline Age, years & $65(18-91)$ & $64(27-82)$ & $51(15-81)$ & $38(15-83)$ & $<0.001$ & $<0.001$ \\
\hline Male/female, $\mathrm{n}$ & $46 / 50$ & $12 / 17$ & $29 / 30$ & $23 / 23$ & 1.000 & 0.487 \\
\hline ALT, IU/L & $204(37-3,214)$ & $251(18-4,090)$ & $638(45-5,180)$ & $1,139(172-8,320)$ & $<0.001$ & $<0.001$ \\
\hline ALP, IU/L & $507(150-3,172)$ & $460(173-8,626)$ & $462(107-2,597)$ & $452(142-1,117)$ & 0.854 & 0.543 \\
\hline Total bilirubin, $\mathrm{mg} / \mathrm{dL}$ & $1.1(0.3-36)$ & N/A & $1.8(0.3-22.7)$ & N/A & 0.022 & N/A \\
\hline$\gamma \mathrm{GTP}, \mathrm{IU} / \mathrm{L}$ & $214(17-1,602)$ & N/A & $240(37-1,629)$ & N/A & 0.063 & N/A \\
\hline \multicolumn{7}{|l|}{ Type of DILI, $\mathrm{n}$} \\
\hline Hepatocellular & 57 & 18 & 16 & 18 & $<0.001$ & 0.062 \\
\hline Cholestatic or mixed & 39 & 11 & 43 & 28 & & \\
\hline Number of cancer/non-cancer patients, $n$ & $10 / 86$ & $11 / 18$ & $0 / 59$ & $0 / 46$ & 0.014 & 1 \\
\hline Time to onset, days ${ }^{\dagger}$ & $24(1-1,439)$ & $83(0-1,990)$ & $15(1-322)$ & $8(2-368)$ & 0.163 & 0.003 \\
\hline Drug was continued at onset, $\mathrm{n}$ & 74 & 18 & 30 & 15 & 0.001 & 0.017 \\
\hline Drug was discontinued at onset, $\mathrm{n}$ & 22 & 11 & 29 & 31 & & \\
\hline Course after cessation of the drug, days ${ }^{\dagger}$ & $14(0-120)$ & $14(0-120)$ & $17(0-751)$ & $15(3-155)$ & 0.035 & 0.040 \\
\hline \multicolumn{7}{|l|}{ Risk factors, $\mathrm{n}$} \\
\hline History of alcohol use & 15 & 10 & 4 & 5 & 0.132 & 0.018 \\
\hline No history of alcohol use & 81 & 19 & 55 & 41 & & \\
\hline \multicolumn{7}{|l|}{ Search for non-drug causes, $\mathrm{n}$} \\
\hline Group I completion & 46 & 15 & 44 & 42 & & \\
\hline Group II completion & 36 & 12 & 31 & 28 & & \\
\hline Groups I and II completion & 30 & 10 & 29 & 26 & 0.028 & 0.096 \\
\hline Groups I and II incompletion & 66 & 19 & 30 & 20 & & \\
\hline \multicolumn{7}{|c|}{ Previous information on hepatotoxicity of the drug, $n$} \\
\hline Presence & 88 & 25 & 51 & 40 & 0.415 & 1.000 \\
\hline Absence & 8 & 4 & 8 & 6 & & \\
\hline \multicolumn{7}{|l|}{ Eosinophilia ( $\geq 6 \%$ ), $n$} \\
\hline Presence & 17 & 1 & 29 & 10 & 0.080 & 0.042 \\
\hline Absence & 69 & 26 & 30 & 36 & & \\
\hline & (unknown 10) & (unknown 2) & & & & \\
\hline \multicolumn{7}{|l|}{ Drug-induced lymphocyte stimulation test, $\mathrm{n}$} \\
\hline Performed & 23 & 1 & 58 & 19 & $<0.001$ & $<0.001$ \\
\hline Not performed & 73 & 28 & 1 & 27 & & \\
\hline Positive or semi-positive & $11(47.9 \%)$ & $0(0 \%)$ & $24(41.4 \%)$ & $0(0 \%)$ & 0.389 & $<0.001$ \\
\hline Negative & $12(52.1 \%)$ & $1(100 \%)$ & $34(58.6 \%)$ & $19(100 \%)$ & & \\
\hline \multicolumn{7}{|l|}{ Response to unexpected readministration, $\mathrm{n}$} \\
\hline Presence & 3 & 0 & 1 & 0 & 1.000 & 1.000 \\
\hline Absence & 93 & 29 & 58 & 46 & & \\
\hline \multicolumn{7}{|c|}{ Definitive diagnostic basis of DILI by experts, $n$} \\
\hline Clinical course & 80 & & 27 & & & \\
\hline DLST & 9 & & 17 & & & \\
\hline Liver biopsy & 5 & & 14 & & & \\
\hline Re-administration of suspicious drugs & 2 & & 1 & & & \\
\hline \multicolumn{7}{|l|}{ Liver diseases in patients without DILI, $\mathrm{n}^{\ddagger}$} \\
\hline Non-alcoholic fatty liver disease & & $10(4)$ & & 0 & & \\
\hline Alcoholic liver disease & & $5(2)$ & & 0 & & \\
\hline Biliary tract disease & & $5(0)$ & & $2(0)$ & & \\
\hline Autoimmune hepatitis & & $4(3)$ & & $2(0)$ & & \\
\hline Viral hepatitis & & $4(1)$ & & $41(3)$ & & \\
\hline Shock liver & & $1(0)$ & & $1(1)$ & & \\
\hline
\end{tabular}

${ }^{\dagger}$ Patients with unknown data are excluded.

${ }^{*}$ Numbers in parentheses indicate the number of patients with a total score of $\geq 3$.

$\mathrm{n}$ : number of patients, ALT: alanine aminotransferase, ALP: alkaline phosphatase, $\gamma$ GTP: $\gamma$-glutamyl transpeptidase, DILI: drug-induced liver injury Values are expressed as median (minimum - maximum), unless otherwise indicated. 
Table 2. DDW-J 2004 Scale Score Items.

\begin{tabular}{|c|c|c|c|}
\hline & New DILI group $(\%)$ & Old DILI group (\%) & $\mathrm{p}$ value \\
\hline \multicolumn{4}{|c|}{ 1. Time to onset } \\
\hline 0 or 1 & $46(47.9)$ & $42(71.2)$ & 0.005 \\
\hline 2 & $50(52.1)$ & $17(28.8)$ & \\
\hline \multicolumn{4}{|c|}{ 2. Course after cessation of the drug } \\
\hline $0-2$ & $75(78.1)$ & $55(93.2)$ & 0.014 \\
\hline 3 & $21(21.9)$ & $4(6.8)$ & \\
\hline \multicolumn{4}{|c|}{ 3. Risk factors (ethanol) } \\
\hline 0 & $81(84.4)$ & $55(93.2)$ & 0.132 \\
\hline 1 & $15(15.6)$ & $4(6.8)$ & \\
\hline \multicolumn{4}{|c|}{ 4. Search for non-drug causes } \\
\hline$-2-1$ & $71(74.0)$ & $21(35.6)$ & $<0.001$ \\
\hline 2 & $25(26.0)$ & $38(64.4)$ & \\
\hline \multicolumn{4}{|c|}{ 5. Previous information on hepatotoxicity of the drug } \\
\hline 0 & $8(8.3)$ & $8(13.6)$ & 0.415 \\
\hline 1 & $88(91.7)$ & $51(86.4)$ & \\
\hline \multicolumn{4}{|c|}{ 6. Eosinophilia ${ }^{\dagger}$} \\
\hline 0 & $79(82.3)$ & $39(66.1)$ & 0.032 \\
\hline 1 & $17(17.7)$ & $20(33.9)$ & \\
\hline \multicolumn{4}{|c|}{ 7. Drug-induced lymphocyte stimulation test } \\
\hline 0 & 85 (88.6) & $35(59.3)$ & $<0.001$ \\
\hline 1 & $1(1.0)$ & $7(11.9)$ & \\
\hline 2 & $10(10.4)$ & $17(28.8)$ & \\
\hline \multicolumn{4}{|c|}{ 8. Response to unexpected readministration } \\
\hline 0 & $93(96.9)$ & $58(98.3)$ & 1.000 \\
\hline 3 & $3(3.1)$ & $1(1.7)$ & \\
\hline
\end{tabular}

Values are expressed as number of patients (percent).

${ }^{\dagger}$ The score for patients with unknown eosinophil count was set to 0 .

formed in $98.4 \%$ of patients in the old DILI group but in only $24.0 \%$ of patients in the new DILI group. However, the positivity rate did not differ markedly between these groups. Suspected drugs were accidentally re-administered to only a few patients.

In the new DILI group, the most frequent diagnostic basis for the condition used by experts was the clinical course and a decrease in the number of liver biopsies. The reason for this decision was that the prevalence of mild DILI increased, and an invasive liver biopsy was avoided.

Regarding liver disease in new and old non-DILI patients, we noted a decrease in viral hepatitis in the new non-DILI group that was easily excluded by the DDW-J 2004 scale. All four relevant patients were diagnosed with acute hepatitis, including one associated with $\mathrm{HBV}$ and three associated with EBV. Viral hepatitis was more common in the old nonDILI group, including 13 cases due to HBV, 11 due to HAV, 10 due to EBV, 5 due to $\mathrm{HCV}$, and 2 due to other causes. Of these 41 cases, 39 had acute hepatitis, and 2 had initially been diagnosed with chronic hepatitis C. Conversely, the in- cidence of NAFLD and AIH, which were difficult to exclude using the DDW-J 2004 scale, were both increased in the new non-DILI group.

Table 2 shows differences in the scores of each diagnostic item of the DDW-J 2004 scale between the new and old DILI group. Although there was no marked difference in the time to the onset (Table 1), patients in the new DILI group showed a more typical course for DILI, so a larger percentage $(52.1 \%)$ received the highest score possible (2 points) than in the old DILI group (28.8\%). Similarly, patients in the new DILI group also had a more typical liver injury recovery course after cessation of the drug than those in the old DILI group, so more patients $(21.9 \%)$ in the new DILI group received the highest score possible (3 points) than in the old DILI group (6.8\%). No marked differences in the history of alcohol use were observed. In the new DILI group, searches for non-drug causes were often not completed, so only $26.0 \%$ of patients received the highest score possible ( 2 points). In both subgroups, many patients were scored for items related to previous information about hepa- 

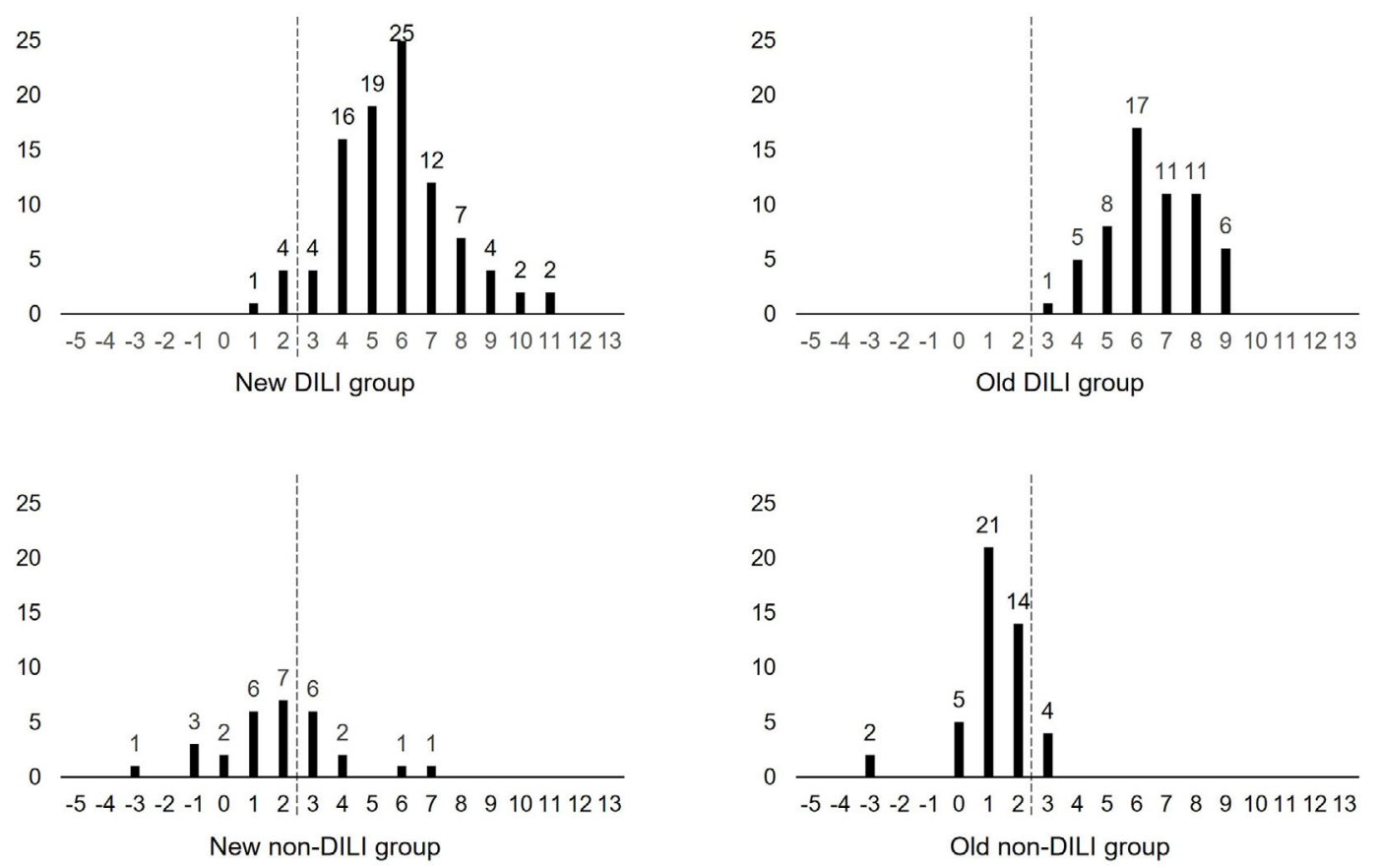

Figure 2. The comparison of the diagnostic ability of the DDW-J 2004 scale in two different eras. Bar graphs show the distributions of total scores of the four subgroups calculated by the DDW-J 2004 scale. The vertical and horizontal axes represent the number of patients and total score, respectively. The vertical dashed line is the border of DILI or non-DILI, defined by the DDW-J 2004 scale. Patients in the new DILI group had significantly lower total scores than those in the old DILI group. The new patients groups showed a sensitivity of $94.8 \%$ and a positive predictive value of $90.1 \%$. However, the specificity and negative predictive value were significantly lower than those in the old patients group.

totoxicity associated with the drug. Regarding eosinophilia, $82.3 \%$ of patients in the new DILI group were not scored because they did not have eosinophilia or had not had eosinophil counts performed. Patients in the new DILI group did not have the opportunity to acquire points for the DLST item due to the low DLST execution rate. No marked differences between the two subgroups were observed with respect to scoring by response to unexpected readministration.

The total scores of the four subgroups and their distributions are shown in Fig. 2 and Table 3. The total score for the new DILI group was significantly lower than that for the old DILI group. Although the sensitivity and PPV remained high, the specificity and NPV were significantly lower in the new patients group than in the old patients group.

Table 4 list the suspicious drugs by subgroup. New drugs that were approved after the DDW-J 2004 scale was proposed were administered to 22 patients in the new DILI group and 6 in the new non-DILI group. No marked differences in the diagnostic ability of the DDW-J 2004 scale were observed between the 28 patients who received new drugs and 97 who received existing drugs in the new patients group (Table 5).

\section{Discussion}

\section{Diagnostic ability of the DDW-J 2004 scale for cur- rent DILI}

More than 15 years have passed since the DDW-J 2004 scale was proposed. In this study, the data from the new patients group and old patients group were separated by at least 10 years and up to 22 years to verify the diagnostic ability of the DDW-J 2004 scale depending on the era. Differences between eras included changes in the understanding of the pathology of DILI, changes in patient background characteristics, identification of other liver diseases, achievement of more detailed differential diagnoses and use of DLST, changes in medical costs, approval of new drugs, and an increased awareness of DILI among clinicians. The results of this study suggest that, despite the changing circumstances surrounding DILI, the DDW-J 2004 scale can be applied to current DILI cases.

\section{Impact of study limitations concerning patient back- grounds}

The impact of the present study's limitations on our findings cannot be ignored. Differences in patient background characteristics and clinical findings influenced the DDW-J 2004 scale scoring. In this study, the severity of liver dam- 
Table 3. Comparison of Diagnostic Ability of DDW-J 2004 Scale in Two Different Eras.

\begin{tabular}{lcc}
\hline \multicolumn{3}{l}{ a) Difference in total score determined by the DDW-J 2004 scale } \\
\hline \multicolumn{2}{l}{ Total score } & $\mathrm{p}$ value \\
\hline $\begin{array}{l}\text { DILI group } \\
\text { New DILI group }\end{array}$ & $6(1-11)$ & 0.004 \\
$\quad$ Old DILI group & $6(3-9)$ & \\
\hline Non-DILI group & & \\
$\quad$ New non-DILI group & $2(-3-7)$ & 0.144 \\
$\quad$ Old non-DILI group & $1(-3-3)$ & \\
\hline
\end{tabular}

Total scores are expressed as median (minimum - maximum).

\begin{tabular}{|c|c|c|c|}
\hline Total score & $\geq 3$ & $\leq 2$ & \\
\hline \multicolumn{4}{|l|}{ Subgroup } \\
\hline New DILI group, $\mathrm{n}$ & 91 & 5 & \\
\hline New non-DILI group, $\mathrm{n}$ & 10 & 19 & \\
\hline Total score & $\geq 3$ & $\leq 2$ & \\
\hline \multicolumn{4}{|l|}{ Subgroup } \\
\hline Old DILI group, $\mathrm{n}$ & 59 & 0 & \\
\hline Old non-DILI group, $\mathrm{n}$ & 4 & 42 & \\
\hline \multicolumn{4}{|l|}{$\mathrm{n}$ : number of patients } \\
\hline \multicolumn{4}{|c|}{$\begin{array}{l}\text { c) The sensitivity, specificity, positive predictive value, and negative predictive } \\
\text { value for the new and old patient groups. }\end{array}$} \\
\hline & New patients group & Old patients group & $\mathrm{p}$ value \\
\hline Sensitivity & $94.8 \%$ & $100 \%$ & 0.086 \\
\hline Specificity & $65.6 \%$ & $91.4 \%$ & 0.013 \\
\hline Positive predictive value & $90.1 \%$ & $93.7 \%$ & 0.313 \\
\hline Negative predictive value & $79.2 \%$ & $100 \%$ & 0.005 \\
\hline
\end{tabular}

age at the onset was mild, and the period from discontinuation of the causative drug to the improvement of liver damage was shorter in the new DILI group than in the old DILI group. The time to the onset from the drug administration and clinical course after cessation of the drug were more consistent with DILI in the new DILI group than in the old DILI group. However, patients in the new and old patients groups were enrolled in two different hospitals, which may have influenced their backgrounds, such as the severity of liver damage, baseline diseases for which the drug was administered, and type of suspected drug. In addition, the old patients group did not include patients with cancer. While such patients were not intentionally excluded, liver dysfunction following the administration of anticancer agents might not have been registered as DILI in older medical record management systems. The factors described above are considered to be weaknesses of this retrospective study (16).

However, a review of previous peer-reviewed reports $(10-12,15)$ that mentioned scoring using the DDW-J 2004 scale in PubMed and the Igaku-Chuo-Zasshi database revealed that despite differences in eras, data collection method, successfully performing a differential diagnosis and DLST, and types of facilities in which the studies were conducted, the median total DDWJ-2004 scale score was 6 or 7 among patients with DILI, suggesting high sensitivity (Table 6). Concerning the type of DILI, which can also influence the time to the onset and to the improvement of DILI, the incidence of hepatocellular injury-type DILI has increased, as shown in a recent report (12).

\section{Changes in other liver diseases and achievement of a differential diagnosis and DLST}

Changes were also observed in the list of other liver diseases that require differentiation from DILI. The DDW-J 2004 scale allows the straightforward exclusion of common viral hepatitis, such as HAV, HBV, and HCV. However, changes in the conception and epidemiology of liver disease, such as hepatitis E (HEV), for which a biological examination had not been commercialized at the time; NAFLD, which was previously not well recognized among Japanese hepatologists at the time the DDW-J 2004 scale was proposed; and acute-onset $\mathrm{AIH}(17,18)$, which remains difficult 
Table 4. Suspicious Drugs.

\begin{tabular}{|c|c|c|c|c|}
\hline \multicolumn{5}{|l|}{ I. New patients group } \\
\hline & \multicolumn{2}{|r|}{ New DILI group } & \multicolumn{2}{|r|}{ New non-DILI group } \\
\hline & Number & Name of suspicious drug & Number & Name of suspicious drug \\
\hline Anti-allergy drugs & $3(0)$ & $\begin{array}{l}\text { cetirizine hydrochloride, pranlukast hydrate, olopatadine } \\
\text { hydrochloride }\end{array}$ & 0 & \\
\hline Anticancer drugs & $6(3)$ & $\begin{array}{c}\text { axitinib, bevacizumab, regorafenib hydrate, tamoxifen, } \\
\text { tegafur/uracil } \times 2\end{array}$ & 0 & \\
\hline $\begin{array}{l}\text { Anti-inflammatory } \\
\text { drugs }\end{array}$ & $5(1)$ & $\begin{array}{l}\text { chlorpheniramine maleate, loxoprofen sodium hydrate } \times 2 \text {, } \\
\text { OTC, tramadol hydrochloride/acetaminophen }\end{array}$ & $3(0)$ & aspirin, $\mathrm{OTC} \times 2$ \\
\hline Antilipidemic drugs & $3(0)$ & atorvastatin calcium $\times 2$, pitavastatin calcium & $2(1)$ & fenofibrate, pitavastatin calcium \\
\hline Antimicrobial drugs & $23(4)$ & $\begin{array}{c}\text { ampicillin sodium and sulbactam sodium, cefazolin sodium } \times 3 \text {, } \\
\text { cefcapene pivoxil hydrochloride hydrate } \times 5 \text {, } \text { cefditoren } \\
\text { pivoxil, cefotiam hydrochloride } \times 2, \text { ceftriaxone sodium } \times 2 \text {, } \\
\text { ciprofloxacin, clindamycin hydrochloride, doripenem } \\
\text { monohydrate, isoniazid, meropenem, minocycline } \\
\text { hydrochloride, piperacillin sodium and tazobactam } \times 2, \\
\text { tosufloxacin tosilate }\end{array}$ & $8(2)$ & $\begin{array}{l}\text { cefditoren pivoxil, cefditoren } \\
\text { pivoxil } \times 2 \text {, cefoperazone sodium and } \\
\text { sulbactam sodium, cefteram pivoxil, } \\
\text { clarithromycin, unknown } \times 2\end{array}$ \\
\hline $\begin{array}{l}\text { Drugs for the } \\
\text { cardiovascular } \\
\text { system }\end{array}$ & $5(2)$ & $\begin{array}{l}\text { calcium polystyrene sulfonate, frosemide, irbesartan and } \\
\text { amlodipine besilate, lomerizine hydrochloride, olmesartan }\end{array}$ & $2(2)$ & telmisartan $\times 2$ \\
\hline $\begin{array}{l}\text { Chinese herbal } \\
\text { medicines }\end{array}$ & $9(0)$ & $\begin{array}{c}\text { Daisaiko, Hangeshashinto, Junchoto, Kakkon'oren'ogonto, } \\
\text { Ninjinyoeito, Orengedokuto, Ryugareikanto, } \\
\text { Saikokaryukotsuboreito, Shakuyakukanzoto }\end{array}$ & $2(0)$ & Eppikajutsuto, Maoto \\
\hline Dietary supplements & $7(0)$ & Details are unknown. & $2(0)$ & Details are unknown. \\
\hline $\begin{array}{l}\text { Drugs for the } \\
\text { gastrointestinal } \\
\text { system }\end{array}$ & $6(2)$ & $\begin{array}{c}\text { antibiotics-resistant lactic acid bacteriae, metoclopramide } \\
\text { hydrochloride, mosapride citrate dihydrate, } \\
\text { sennosides,vonoprazan fumarate } \times 2\end{array}$ & $1(0)$ & rebamipide \\
\hline $\begin{array}{l}\text { Hematopoietic and } \\
\text { anticoagulant drugs }\end{array}$ & $1(1)$ & clopidogrel & 0 & \\
\hline Hormonal agents & $3(0)$ & conjugated estrogens, cyclofenil, levothyroxine sodium & 0 & \\
\hline Metabolic agents & $10(6)$ & $\begin{array}{l}\text { benzbromarone, disulfiram, febuxostat, fingolimod } \\
\text { hydrochloride, glimepiride, glycyrrhizic acid, iron sucrose, } \\
\text { linagliptin, methotrexate, mitiglinide calcium dihydrate, }\end{array}$ & $2(0)$ & $\begin{array}{l}\text { glimepiride, sodium risedronate } \\
\text { hemipentahydrate }\end{array}$ \\
\hline $\begin{array}{l}\text { Drugs for psychiatric } \\
\text { and neurological } \\
\text { systems }\end{array}$ & $12(2)$ & $\begin{array}{c}\text { betahistine mesilate, carbamazepine, carbidopa hydrate and } \\
\text { levodopa } \times 2 \text {, donepezil hydrochloride, escitalopram oxalate, } \\
\text { ifenprodil tartrate, lorazepam, phenytoin, pregabalin, tranilast, } \\
\text { valproate sodium, }\end{array}$ & $4(0)$ & $\begin{array}{l}\text { alprazolam, betahistine mesilate, } \\
\text { phenytoin, tranilast }\end{array}$ \\
\hline $\begin{array}{l}\text { Drugs for a } \\
\text { urogenital system }\end{array}$ & $2(1)$ & flavoxate hydrochloride, mirabegron & $1(1)$ & tamsulosin hydrochloride \\
\hline Others & $1(0)$ & some kind of food & $2(0)$ & some kind of food $\times 2$ \\
\hline
\end{tabular}

Numbers in parentheses indicate new drugs approved after introduction of the DDW-J 2004 scale. The new drugs are shown in italic and bold font. OTC: over-the-counter drug

to diagnose even by hepatologists, might affect the diagnostic specificity and NPV of the DDW-J 2004 scale.

In the new DILI group, most patients were tested for HBV and HCV. The exclusion of ALD by history taking and shock liver by a physical examination was also sufficient. However, examinations of biliary tract disease by imaging tests and of virus-related markers for HAV, EBV, and CMV were sometimes omitted. The number of patients who received DLST was also small.

There is no definitive biomarker for the diagnosis of DILI, so the differential diagnosis from other liver diseases and DLST is important and can affect the diagnostic ability of the DDW-J 2004 scale. However, high diagnostic costs cannot be ignored and might result in hesitation to make a detailed differential diagnosis and perform DLST.

\section{Diagnostic ability of the DDW-J 2004 scale for new drugs and new types of DILI}

Since the proposal of the DDW-J 2004 scale, numerous drugs with novel mechanisms of action and effects, which have been adopted as major treatments for common diseases and intractable disease in various body systems, have been developed. The new patients group in the present study received some of these new drugs, and the diagnostic potential of DDW-J 2004 scale for DILI caused by these new drugs was satisfied. Nevertheless, the new DILI group included two patients who experienced tamoxifen- (one patient) and estrogen-induced steatohepatitis (one patient) (19), which were diagnosed by experts. However, the cases were each given a score of 2 points (low possibility) on the DDW-J 2004 scale. It may be difficult to diagnose drug-induced steatohepatitis using the DDW-J 2004 scale, the concept and 
Table 4. Suspicious Drugs. (Continued)

\begin{tabular}{|c|c|c|c|c|}
\hline \multicolumn{5}{|l|}{ II. Old patients group } \\
\hline & \multicolumn{2}{|r|}{ Old DILI group } & \multicolumn{2}{|r|}{ Old non-DILI group } \\
\hline & Number & Name of suspicious drug & Number & Name of suspicious drug \\
\hline Anti-allergy drugs & 3 & $\begin{array}{l}\text { dexchlorpheniramine maleate, mequitazine, } \\
\text { phenylpropanolamine hydrochloride }\end{array}$ & 1 & mequitazine \\
\hline Anticancer drugs & 0 & & 1 & tegafur/uracil \\
\hline $\begin{array}{l}\text { Anti-inflammatory } \\
\text { drugs }\end{array}$ & 9 & $\begin{array}{c}\text { aspirin, cold remedy } \times 3 \text {, ibuprofen, loxoprofen sodium } \\
\text { hydrate, naproxen, OTC } \times 2\end{array}$ & 19 & $\begin{array}{l}\text { aspirin } \times 3 \text {, cold remedy } \times 2 \text {, diclofenac } \\
\text { sodium, ibuprofen, loxoprofen } \\
\text { sodium hydrate } \times 4, \text { OTC } \times 8\end{array}$ \\
\hline Antilipidemic drugs & 1 & atorvastatin calcium & 0 & \\
\hline Antimicrobial drugs & 8 & $\begin{array}{l}\text { cefcapene pivoxil hydrochloride hydratex2, cefozopran } \\
\text { hydrochloride, cefpodoxime proxetil, clarithromycin, } \\
\text { fleroxacin, isoniazid, minocycline hydrochloride }\end{array}$ & 10 & $\begin{array}{c}\text { azithromycin hydrate, cefaclor, } \\
\text { cefazolin sodium hydrate, cefdinir } \times 2 \text {, } \\
\text { cefotiam hydrochloride, } \\
\text { clarithromycin, erythromycin, } \\
\text { levofloxacin } \times 2\end{array}$ \\
\hline $\begin{array}{l}\text { Drugs for the } \\
\text { cardiovascular } \\
\text { system }\end{array}$ & 1 & propranolol hydrochloride & 2 & $\begin{array}{l}\text { diltiazem hydrochloride, tocopherol } \\
\text { ticotinate }\end{array}$ \\
\hline $\begin{array}{l}\text { Chinese herbal } \\
\text { medicines }\end{array}$ & 4 & Hachimijiogan, Kakkonto $\times 2$, Mutsugan & 0 & \\
\hline Dietary supplements & 3 & Details are unknown. & 0 & \\
\hline $\begin{array}{l}\text { Drugs for the } \\
\text { gastrointestinal } \\
\text { system }\end{array}$ & 5 & $\begin{array}{l}\text { azulene sulfonate sodium and L-glutamine, cimetidine } \times 2, \\
\text { ranitidine hydrochloride, teprenone }\end{array}$ & 9 & $\begin{array}{l}\text { antibiotics-resistant lactic acid } \\
\text { bacteriae, cimetidine, domperidone, } \\
\text { famotidine } \times 2 \text {, infliximab, OTC } \times 3\end{array}$ \\
\hline $\begin{array}{l}\text { Hematopoietic and } \\
\text { anticoagulant drugs }\end{array}$ & 3 & ticlopidine $\times 3$ & 0 & \\
\hline Hormonal agents & 2 & betamethasone, levonorgestrel & 0 & \\
\hline Metabolic agents & 3 & allopurinol, camostat mesylate, tiopronin & 1 & mecobalamin \\
\hline $\begin{array}{l}\text { Drugs for psychiatric } \\
\text { and neurological } \\
\text { systems }\end{array}$ & 10 & $\begin{array}{c}\text { chlorpromazine hydrochloride, halothane } \times 2 \text {, methylphenidate } \\
\text { hydrochloride, phenobarbital, setiptiline maleate, tizanidine } \\
\text { hydrochloride, tofisopam, tranilast, vegetamin }\end{array}$ & 0 & \\
\hline $\begin{array}{l}\text { Drugs for a } \\
\text { urogenital system }\end{array}$ & 1 & tamsulosin hydrochloride & 2 & $\begin{array}{l}\text { flavoxate hydrochloride, sildenafil } \\
\text { citrate }\end{array}$ \\
\hline Others & 6 & $\begin{array}{c}\text { cough medicine } \times 2 \text {, some kind of food } \times 2 \text {, Kallidinogenase, } \\
\text { OTC }\end{array}$ & 1 & theophylline \\
\hline
\end{tabular}

OTC: over-the-counter drug

Table 5. Differences in Total Score of Liver Injury Caused by New Drugs and Existing Drugs in the New Patients Group.

\begin{tabular}{|c|c|c|c|c|c|}
\hline & \multicolumn{2}{|c|}{ Patients who received new drugs } & \multicolumn{3}{|c|}{ Patients who received existing drugs } \\
\hline Total score & $\geq 3$ & $\leq 2$ & $\geq 3$ & $\leq 2$ & \\
\hline \multicolumn{6}{|l|}{ Subgroup } \\
\hline New DILI group, $\mathrm{n}$ & 22 & 0 & 69 & 5 & \\
\hline \multirow[t]{2}{*}{ New non-DILI group, $\mathrm{n}$} & 1 & 5 & 9 & 14 & \\
\hline & \multicolumn{2}{|c|}{ Patients who received new drugs } & \multicolumn{2}{|c|}{ Patients who received existing drugs } & $\mathrm{p}$ value \\
\hline Sensitivity & \multicolumn{2}{|c|}{$100 \%$} & \multicolumn{2}{|c|}{$93.3 \%$} & 0.264 \\
\hline Specificity & \multicolumn{2}{|c|}{$83.4 \%$} & \multicolumn{2}{|c|}{$60.9 \%$} & 0.302 \\
\hline Positive predictive value & \multicolumn{2}{|c|}{$95.7 \%$} & \multicolumn{2}{|c|}{$88.5 \%$} & 0.284 \\
\hline Negative predictive value & \multicolumn{2}{|c|}{$100 \%$} & \multicolumn{2}{|c|}{$73.7 \%$} & 0.274 \\
\hline
\end{tabular}

$\mathrm{n}$ : number of patients

causative agent of which have already been recognized. Therefore, if the DDW-J 2004 scale is revised in the future, these drugs should be included. Furthermore, it should be noted that immune checkpoint inhibitors, which cause immune-related adverse events (irAEs) $(4,20)$, were not in- cluded in this study. Other new drugs will continue to be developed, so it is necessary to constantly verify the validity of new drugs and add comments if any are missing to keep the scale updated. 
Table 6. Review of Past Reports Showing Assessment Using the DDW-J 2004 Scale.

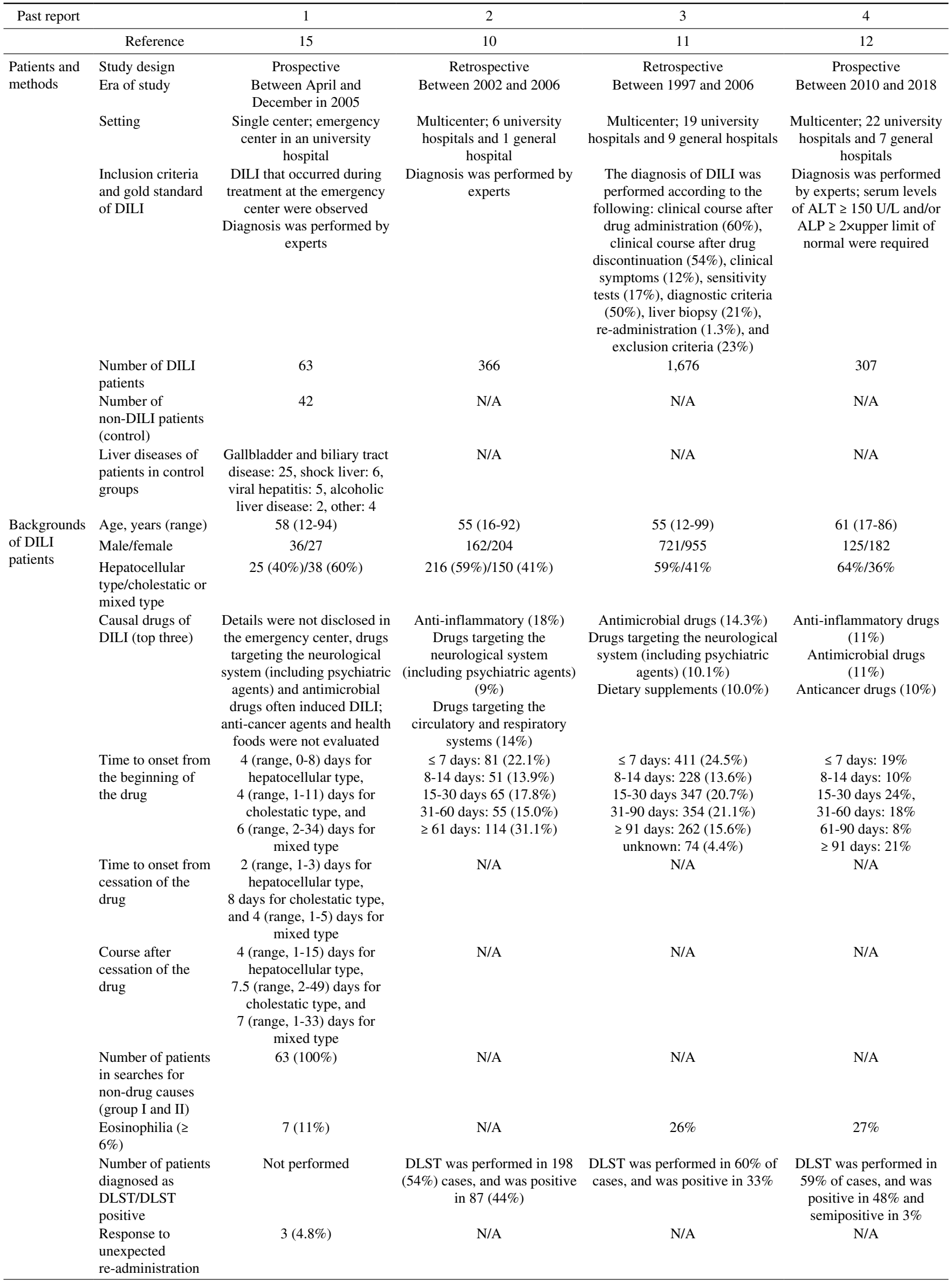


Table 6. Review of Past Reports Showing Assessment Using the DDW-J 2004 Scale. (Continued)

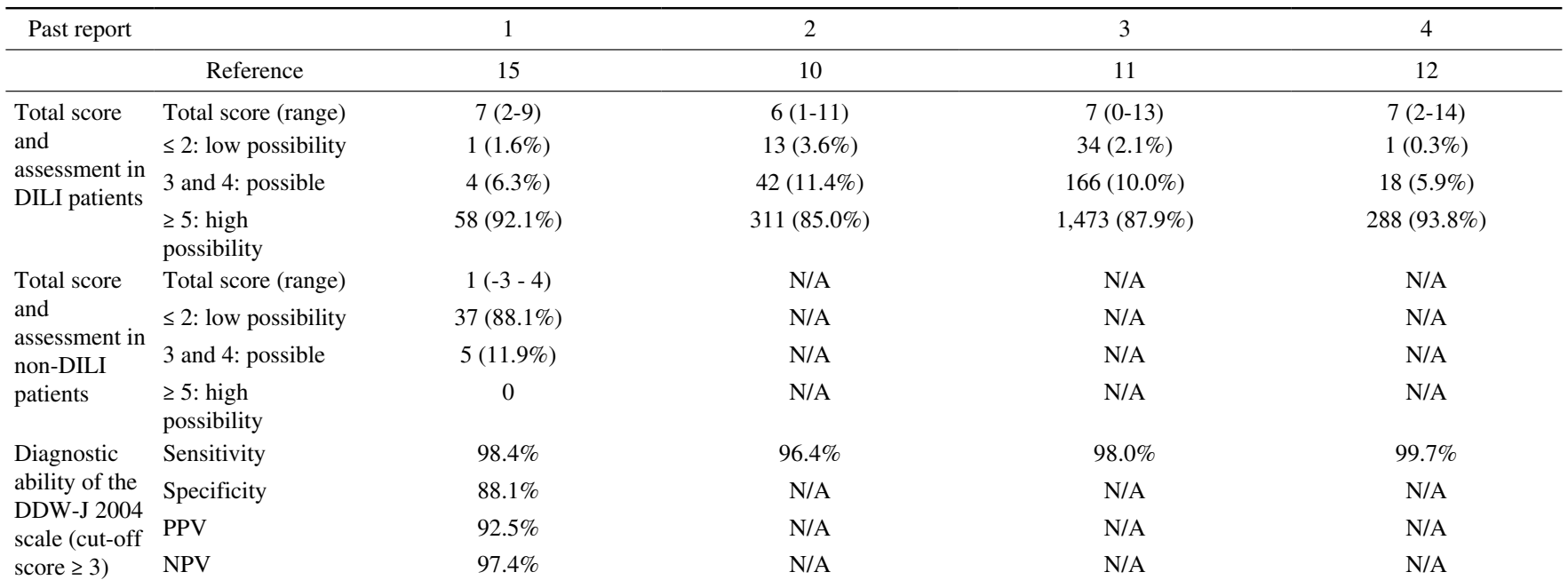

DILI: drug-induced liver injury, ALT: alanine aminotransferase, ALP: alkaline phosphatase, DLST: drug-induced lymphocyte stimulation test, PPV: positive predictive value, NPV: negative predictive value

\section{Differences between the DDW-J 2004 scale and up- dated RUCAM}

It should be noted that the RUCAM scale (7) and DDW-J 2004 scale $(8,11)$ have different purposes and uses. Nevertheless, the DDW-J 2004 scale appears to be less wellknown worldwide than the RUCAM scale, considering the number of citations in reviews and research. Although the DDW-J 2004 scale was published in English (8), it remains unreadable online; this may be one of the obstacles hampering its global recognition. Note that a review article published in 2009 containing the key table of the DDW-J 2004 scale is available on the web (11).

The RUCAM scale was introduced in 1993 and updated in 2016 (21) with the purpose of assessing liver damage caused by Chinese herbs. The configuration of diagnostic items in the updated version is similar to that in the original version. Regarding alcohol intake, which is considered to be a risk factor of DILI, the amount of alcohol was determined by gender. However, the differential diagnosis was further strengthened. The seven causes of HAV, HBV, HCV, HEV, biliary tract disease, alcoholism, and a recent history of acute hypotension are categorized into group I, while the five causes of complications of underlying diseases (sepsis, metastatic malignancy, AIH, chronic $\mathrm{HBV}$ or $\mathrm{HCV}$ infection, $\mathrm{PBC}$, primary sclerosing cholangitis, and genetic liver diseases), CMV, EBV, herpes simplex virus, and varicellazoster virus are categorized into group II. If both groups are evaluated, the highest score that can be obtained is 2 . When group I causes are completely excluded, only 1 point can be obtained, and if fewer than five diseases from group I are considered, 2 points are deducted (21). In addition, the evaluation methods for the differential diagnosis are also specified in great detail, and some of them, e.g. anti-HEVIgM, HEV-RNA, and anti-CMV-IgG, are not common in Ja- pan. A checklist of these diseases was included as an appended table.

The RUCAM scale aims to be a common basic tool for clinical, regulatory, publication, and expert purposes $(7,21,22)$. While it is a more precise and strict causality assessment scale than the DDW-J 2004 scale (21-23), it may be inconvenient for daily clinical use for evaluation of DILI by non-hepatologists. At the DDW-J 2002 symposium that proposed a scale based on the RUCAM scale, the diagnostic item regarding "concomitant drug" in the RUCAM scale was deleted, as it carried a risk of underestimating DILI in Japanese patients, who commonly use concomitant drugs $(1,2)$. Indeed, 180 of $230(78.3 \%)$ patients in this study were receiving concomitant drugs. The items for differentiation were simplified to eight common liver diseases: HAV, HBV, HCV, biliary tract disease, shock liver, EBV, and CMV. Subsequently, to assess allergic reactions, eosinophilia and DLST were added as diagnostic items (1).

The DDW-J 2002 causality assessment scale was evaluated to confirm its ability to accurately diagnose DILI in Japanese cases that had been overlooked using the RUCAM scale (2). Thereafter, the DDW-J 2004 scale was proposed based on the DDW-J 2002 causality assessment scale (8). In Japan, the DDW-J 2004 scale has commonly been used as a unified standard for the diagnosis of, research into, and case reporting for DILI. One of the purposes of the DDW-J 2004 scale is to function as a simple scale for use by clinicians other than hepatologists (8). It is accompanied by a detailed user manual and includes a recommendation that cases that are difficult to diagnose or have severe liver injury be promptly referred to a hepatologist (8). As mentioned above, using the DDW-J 2004 scale, inadequate differential diagnoses can reduce scores, but typical DILI patients will not be overlooked if their basic information, such as the time to the onset after administration, course after cessation of the drug, 
risk factors, and previous information on hepatotoxicity of the drug, are met $(11,12,15)$. Therefore, if the DDW-J 2004 scale is updated in the future, the updated RUCAM should be cited carefully to avoid making the diagnosis of DILI in Japan more complicated that it needs to be.

\section{Conclusion}

The DDW-J 2004 scale maintains a stable diagnostic ability for typical DILI, regardless of differences in patient background characteristics between eras and differences in verification methods. Nevertheless, the medical cost for the evaluation should also be considered, as well as the fact that inadequate differential diagnoses may affect scoring. While new drugs do not influence the diagnosis, new types of DILI, such as irAEs, must be addressed. Therefore, it may be time to consider updating the DDW-J 2004 scale.

The authors state that they have no Conflict of Interest (COI).

\section{References}

1. Takikawa H, Takamori Y, Kumagi T, et al. Assessment of 287 Japanese cases of drug induced liver injury by the diagnostic scale of the International Consensus Meeting. Hepatol Res 27: 192-195, 2003.

2. Watanabe M, Shibuya A. Validity study of a new diagnostic scale for drug-induced liver injury in Japan - comparison with two previous scales. Hepatol Res 30: 148-154, 2004.

3. Masumoto T, Horiike N, Abe M, et al. Diagnosis of drug-induced liver injury in Japanese patients by criteria of Consensus Meetings in Europe. Hepatol Res 25: 1-7, 2003.

4. Hoofnagle JH, Björnsson ES. Drug-induced liver injury - types and phenotypes. N Engl J Med 381: 264-273, 2019.

5. Andrade RJ, Aithal GP, Björnsson ES, et al. EASL clinical practice guidelines: drug-induced liver injury. J Hepatol 70: 12221261, 2019.

6. Benichou C. Standardization of definitions and criteria of causality assessment of adverse drug reactions. Drug-induced liver disorders: report of an international consensus meeting. Int J Clin Pharmacol Ther Toxicol 28: 317-322, 1990.

7. Danan G, Benichou C. Causality assessment of adverse reactions to drugs--I. A novel method based on the conclusions of international consensus meetings: application to drug-induced liver injuries. J Clin Epidemiol 46: 1323-1330, 1993.

8. Takikawa H, Onji M. A proposal of the diagnostic scale of drug- induced liver injury. Hepatol Res 32: 250-251, 2005.

9. Takikawa H, Onji M, Takamori Y, et al. Proposal of diagnostic criteria for drug-induced liver injury revised by the DDW-J 2004 Workshop. Kanzo 46: 85-90, 2005 (In Japanese).

10. Takikawa H. Recent status of drug-induced liver injury. Hepatol Res 39: 1-6, 2009.

11. Takikawa H, Murata Y, Horiike N, Fukui H, Onji M. Druginduced liver injury in Japan: an analysis of 1676 cases between 1997 and 2006. Hepatol Res 39: 427-431, 2009.

12. Aiso M, Takikawa H, Tsuji K, et al. Analysis of 307 cases with drug-induced liver injury between 2010 and 2018 in Japan. Hepatol Res 49: 105-110, 2019.

13. Rockey DC, Seeff LB, Rochon J, et al. Causality assessment in drug-induced liver injury using a structured expert opinion process: comparison to the Roussel-Uclaf causality assessment method. Hepatology 51: 2117-2126, 2010.

14. Watanabe M, Shibuya A, Satomichi A, et al. Diagnostic value of drug lymphocyte stimulation test and evaluation of diagnostic criteria for drug induced liver injury. Kanzo 42: 448-454, 2001 (In Japanese).

15. Watanabe M, Shibuya A, Miura Y, et al. Validity study of DDW-J 2004 scoring scale for drug-induced liver injury. Kanzo 48: 219226, 2007 (In Japanese).

16. Danan G, Teschke R. Roussel uclaf causality assessment method for drug-induced liver injury: present and future. Front Pharmacol 10: $853,2019$.

17. Alvarez F, Berg PA, Bianchi FB, et al. International Autoimmune Hepatitis Group report: review of criteria for diagnosis of autoimmune hepatitis. J Hepatol 31: 929-938, 1999.

18. de Boer YS, Kosinski AS, Urban TJ, et al. Features of autoimmune hepatitis in patients with drug-induced liver injury. Clin Gastroenterol Hepatol 15: 103-112, 2017.

19. Farrell GC. Drugs and steatohepatitis. Semin Liver Dis 22: 185194, 2002.

20. De Martin E, Michot JM, Papouin B, et al. Characterization of liver injury induced by cancer immunotherapy using immune checkpoint inhibitors. J Hepatol 68: 1181-1190, 2018.

21. Danan G, Teschke R. RUCAM in drug and herb induced liver injury: the update. Int J Mol Sci 17: 14, 2016.

22. Danan G, Teschke R. Drug-Induced liver injury: why is the Roussel Uclaf Causality Assessment Method (RUCAM) still used 25 years after its launch? Drug Saf 41: 735-743, 2016.

23. Teschke R. Idiosyncratic DILI: analysis of 46,266 cases assessed for causality by RUCAM and published from 2014 to early 2019. Front Pharmacol 23: 730, 2019.

The Internal Medicine is an Open Access journal distributed under the Creative Commons Attribution-NonCommercial-NoDerivatives 4.0 International License. To view the details of this license, please visit (https://creativecommons.org/licenses/ by-nc-nd/4.0/).

(C) 2021 The Japanese Society of Internal Medicine

Intern Med 60: 2557-2568, 2021 